\title{
The efficacy of a pseudo-ceramide and eucalyptus extract containing lotion on dry scalp skin
}

This article was published in the following Dove Press journal: Clinical, Cosmetic and Investigational Dermatology

\author{
Yutaka Takagi' \\ Xuanhe Ning' \\ Akihiko Takahashi' \\ Chiaki Ishizaki² \\ Takahiro Nishizaka' \\ Kazuhiro Kaizu' \\ Masahiro Miyaki' \\ Hotaka Yamamuro' \\ Makoto Kawashima ${ }^{3}$ \\ 'Skin Care Product Research, Kao \\ Corporation, Tokyo, Japan; ${ }^{2}$ Ebisu \\ Skin Research Center, Inforward, \\ Inc., Tokyo, Japan; ${ }^{3}$ Department of \\ Dermatology, Tokyo Women's Medical \\ University, Tokyo, Japan
}

\begin{abstract}
Objective: Dry and scaly conditions on the scalp are often observed in patients with atopic dermatitis, seborrheic dermatitis and/or pityriasis capitis. Those scalp lesions often exhibit low barrier function and reduced ceramide levels. Therefore, a clinical study was conducted to evaluate the efficacy of topical application of a pseudo-ceramide and eucalyptus extract-containing lotion on the scalps of patients with skin diseases.
\end{abstract}

Methods: Thirty-four subjects participated in this study (atopic dermatitis: 19 subjects; seborrheic dermatitis: 6 subjects; pityriasis capitis: 9 subjects). After 4 weeks of daily treatment with a pseudo-ceramide and eucalyptus extract-containing lotion, the skin symptoms had significantly improved in all patients with those skin diseases.

Results: Skin dryness, scaling, and erythema were significantly improved by treatment with the lotion. The moisture-retention ability of the scalp was significantly increased and itchiness, evaluated using a visual analog scale, decreased significantly. Accompanying those improvements was a significant improvement in the quality of life of the subjects, evaluated by the Skindex-16 ${ }^{\circledR}$. Conclusion: From these results, we conclude that this pseudo-ceramide and eucalyptus extractcontaining lotion effectively improved the dry and scaly conditions of the scalp as well as the quality of life of subjects with atopic dermatitis, seborrheic dermatitis, or pityriasis capitis.

Keywords: formulation, skin care, moisturization, scalp lotion, sensitive skin, inflammation

\section{Introduction}

Ceramides are major components of intercellular lipids in the stratum corneum ${ }^{1}$ and play a crucial role in the barrier function ${ }^{2}$ and moisture-retention ability (MRA) of the skin. ${ }^{3}$ Skin with decreased stratum corneum functions, such as seen in patients with atopic dermatitis, ${ }^{4,5}$ has low ceramide levels in the stratum corneum. ${ }^{6,7}$ The efficacy of topically applied ceramides, pseudo-ceramides, or ceramide precursors on atopic dermatitis has been reported..$^{8-13}$

Pruritic inflammatory skin with a reduced cutaneous barrier function and MRA is also observed on the scalps of patients with atopic dermatitis, despite the conditions of high humidity caused by thick hair, and sweat and sebaceous glands. Dry and scaly eruptions on the scalp are also observed in diseases such as seborrheic dermatitis and pityriasis capitis. ${ }^{14}$ Harding et al reported that scalps with dandruff have low ceramide levels. ${ }^{15}$ Thus, an increase in ceramide levels may improve scalp conditions, not only in patients with atopic dermatitis but also in patients with seborrheic dermatitis and/ or pityriasis capitis.

Imokawa et al synthesized a pseudo-ceramide, cetyl PG hydroxyethyl palmitamide (Figure 1), to compensate for natural ceramides ${ }^{8}$ and found that the topical application
Correspondence: Yutaka Takagi Skin Care Product Research, Kao Corporation, 2-I-3 Bunka, Sumida-ku, Tokyo I 3 I-850 I Japan

Tel +81356309792

Fax +81356309330

Email takagi.yutaka@kao.com 
of pseudo-ceramide on the skin of patients with atopic dermatitis and on subjects with sensitive skin enhanced their stratum corneum functions. ${ }^{10,12}$ Furthermore, we reported that a eucalyptus extract is effective in increasing ceramide levels in the epidermis. ${ }^{16}$

In this study, we evaluated the efficacy of a lotion containing pseudo-ceramide and a eucalyptus extract on dry and scaly scalp conditions of patients with atopic dermatitis, seborrheic dermatitis, or pityriasis capitis. Environmental factors are known to affect the functions of the stratum corneum. ${ }^{17}$ Since the scalp is often covered with thick hair and is protected from exposure to the outer environment, we performed this evaluation during the winter season when the meteorological influence is lowest.

\section{Methods}

\section{Subjects}

This evaluation was performed as a single dermatologistcontrolled baseline comparison study and adhered to the tenets of the Declaration of Helsinki. All clinical studies were reviewed and approved by the Review Board of the Shinkohkai Medical Corporation (Tokyo, Japan), and written informed consent was obtained from each subject before the study.

Subjects with dry skin symptoms on their scalp were prescreened from candidates with atopic dermatitis, seborrheic dermatitis, or pityriasis capitis by visual observation and by medical interviews conducted by the dermatologists. Subjects who were receiving medical treatment on the scalp and/or were using anti-dandruff or anti-itchiness materials on the scalp were excluded from the study. They were excluded prior to the screening.

Of the 67 Japanese females who were pre-screened, 33 subjects aged $22-55$ years (mean $=40.5 \pm 9.9$ years) were enrolled in this study. Nineteen subjects with atopic dermatitis (mild: 12 subjects; moderate: 7 subjects, classified by the grading system of Rajka \& Langeland), ${ }^{18} 6$ subjects with seborrheic dermatitis, and 9 subjects with pityriasis capitis were enrolled. Two subjects with moderate atopic dermatitis were taking an oral medical treatment as noted below, and

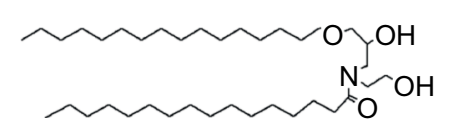

Figure I Structure of the pseudo-ceramide (cetyl PG hydroxyethyl palmitamide) used in this study. none of the subjects were receiving topical medical treatment on the scalp.

\section{Materials}

All test materials used in this study were provided by Kao Corporation (Tokyo, Japan). The test scalp lotion was a fragrance-free, color-free, and weakly acidic, and contained synthetic pseudo-ceramide (cetyl PG hydroxyethyl palmitamide $)^{8}$ and eucalyptus leaf extract. ${ }^{16}$ The other ingredients of the test lotion included: water (aqua), butylene glycol, betaine, glycerin, polyethylene glycol, Thujopsis dolabrata branch extract, L-arginine, sodium methyl stearoyl taurate, and methylparaben.

The test lotion was applied once a day after each patient used a shampoo. Changes of shampoo, conditioner, hair styling products, and/or hair care products during this study were prohibited. Hair perms or coloration were also prohibited.

\section{Evaluations}

Prior to evaluating the efficacy of the scalp lotion, the severity of skin symptoms on each part of the scalp was assessed as follows: The scalp was divided into 23 areas (5 areas on the front and top of the head, 5 areas on the right side of the head, 5 areas on the left side of the head, and 8 areas on the back of the head) as shown schematically in Figure 2. Following acclimation in a climate-controlled room at $20^{\circ} \mathrm{C} \pm 2^{\circ} \mathrm{C}$ and $40 \% \pm 5 \%$ relative humidity for 20 minutes, 2 well-trained specialists performed assessments of scaling and erythema on each area of the scalp. Scaling and erythema were rated on a scale of $1-4$ (1=none, $2=$ mild, $3=$ moderate, and $4=$ severe $)$. Each mean value (0.5) was also obtained as a score. To
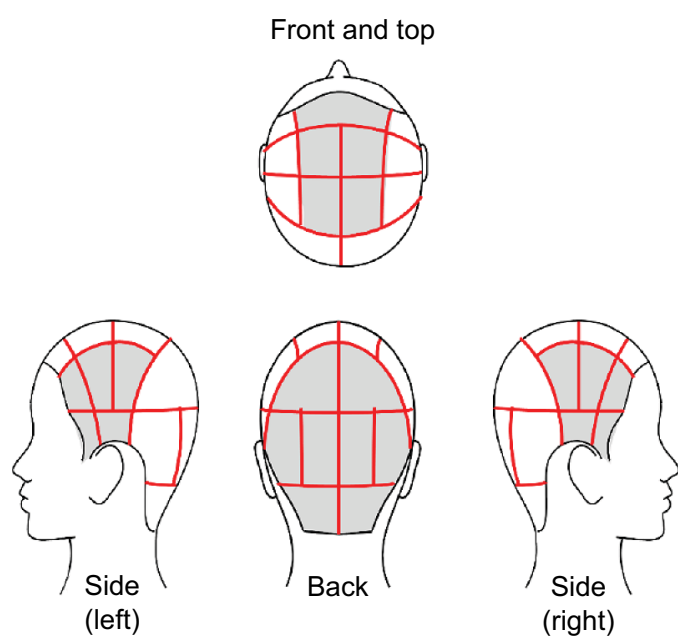

Figure 2 The scalp was divided into 23 areas for the assessment of symptoms that were rated on a scale of $\mathrm{I}-4$. 
compare the severity of scalp skin symptoms between the areas of the head, the average score of each region was used. The skin condition of each area was recorded using a Skin-Watcher ${ }^{\circledR}$ SW-40 (COREFRONT Corp., Tokyo, Japan).

The efficacy of the lotion was assessed from evaluations at the end of weeks 2 and 4 compared with the start of the study (week 0). All assessments were performed at the instrumental analyzing area after removal of the hair with scissors and acclimation in the climate-controlled room at $20^{\circ} \mathrm{C} \pm 2^{\circ} \mathrm{C}$ and $40 \% \pm 5 \%$ relative humidity for 20 minutes. The dermatologist performed assessments of dryness, scaling, erythema, itchiness, and scabbing on the whole scalp, and rated those symptoms on a scale of $1-5$ (1=none, $2=$ slight, $3=$ mild, $4=$ moderate, and $5=$ severe).

\section{Instrumental analysis}

The instrumental measurements were performed on a $10 \times 10$ $\mathrm{mm}$ area on the left side of the head ( $70 \mathrm{~mm}$ above the ear) of each patient, where the hair was removed by scissors. MRA and transepidermal water loss (TEWL) were measured using a Corneometer ${ }^{\circledR}$ (Courage + Khazaka electronic GmbH, Cologne, Germany) and a Vapometer ${ }^{\circledR}$ (Delfin Technologies Ltd, Kuopio, Finland), respectively. The average values of 3 MRA measurements and 2 TEWL measurements were used for analysis.

\section{Subjective evaluation by the test subjects}

Subjective evaluation of the itchiness of the scalp was obtained from each patient using the visual analog scale (VAS). The VAS consisted of a 100-mm horizontal line marked 0 (no itch) to 100 (maximum intensity of itch). Patients marked their itch on this line by themselves. ${ }^{19}$ The quality of life (QoL) was analyzed using the Skindex-16 ${ }^{\circledR} \cdot{ }^{20}$

\section{Judgment of safety}

At the week 4 evaluation, the dermatologist judged the safety and usefulness of the test material. The safety was judged according to a diary kept by each subject and by inquiry on each examination day. In case of interruption of the trial, the suspected cause and reason were described. Immediately after an interruption, an assertion of safety was performed.

\section{Statistical analysis}

All data were statistically analyzed using the one-way repeated measures analysis of variance test or the Wilcoxon signed-rank test using StatView 5.0 (SAS Institute Inc., Cary, NC, USA).

\section{Results}

This study was performed in Tokyo, Japan, from January through February in 2015. The average temperature was $5.8^{\circ} \mathrm{C} \pm 2.0^{\circ} \mathrm{C}$ and the relative humidity was $55.1 \% \pm 17.7 \%$. There were relatively small changes in temperature and relative humidity during this period even though there were daily variations (Figure 3).

In the initial evaluation (week 0), the back of the head had the most severe scaling and erythema, whereas there was less on the side of the head, and least on the front and top of the head (Figure 4). These differences in the severity of skin symptoms based on the head regions were similar to other kinds of skin diseases (data not shown).

Table 1 indicates the changes in severity of skin symptoms following usage of the scalp lotion. There were no statistically significant differences in any of those skin symptoms between the patients with atopic dermatitis and those with the other 2 diseases at week 0 . At the week 4 evaluation, dryness, scaling, erythema, and itchiness were significantly improved in all 34 subjects. Highly significant improvements in scaling, erythema, and itchiness were observed even at week 2 . Scabbing was found only on 5 subjects at the baseline (week 0 ) with a score of 2 , which decreased to 4 subjects at week 4 (no significance, data not shown). The efficacy of the scalp lotion was found to be similar for patients with atopic dermatitis and those with seborrheic dermatitis or pityriasis capitis. Figure 5 shows representative photographs demonstrating the
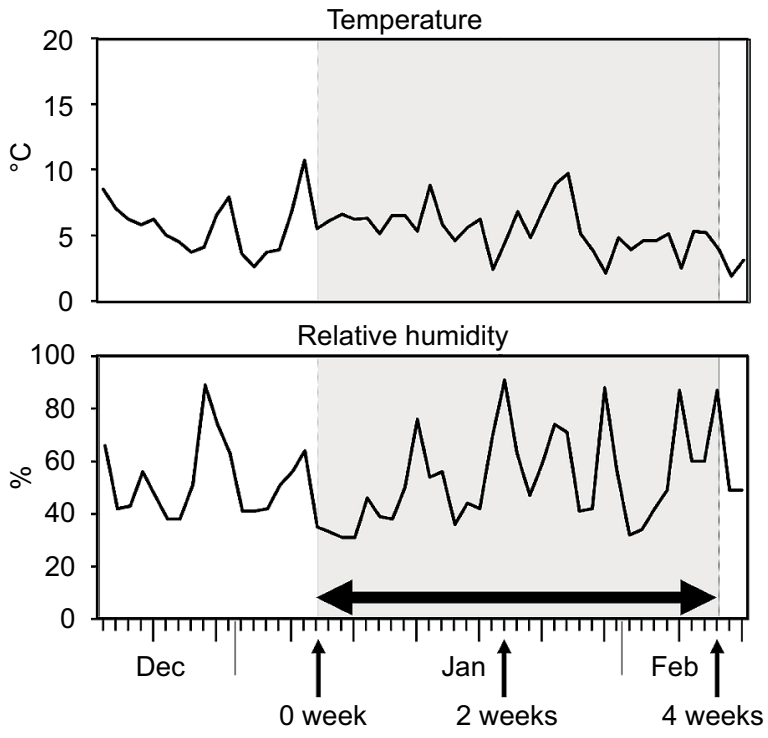

Figure 3 Changes in daily temperature and relative humidity during the evaluation period.

Note: The double-sided horizontal arrow indicates the term of usage of the scalp lotion, and the vertical arrows indicate the evaluation times. 
A

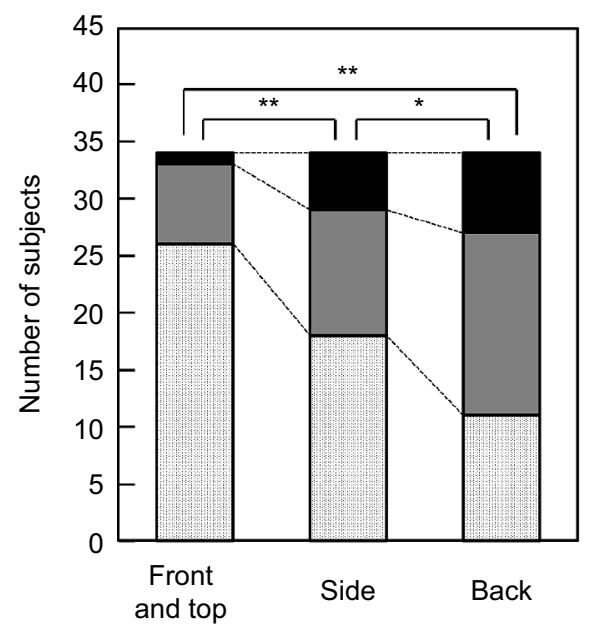

B

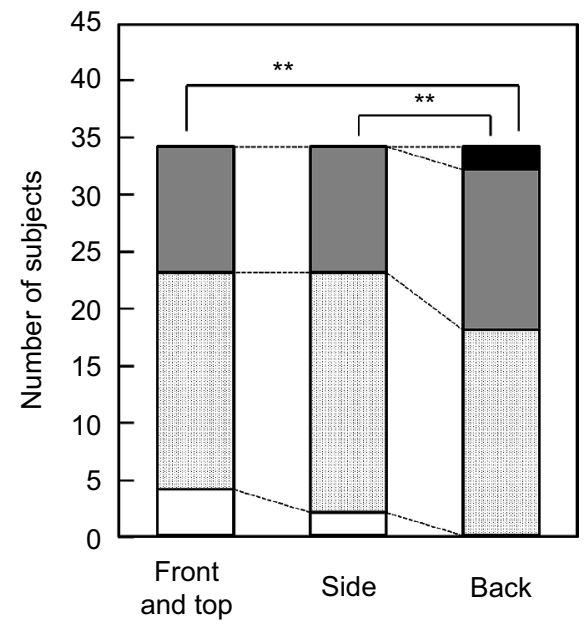

$: \leq 3$

$: \leq 4$

Figure 4 Differences in the severity of scaling $(\mathbf{A})$ and erythema $(\mathbf{B})$ at week 0 in the scalp region.

Notes: Each column indicates the number of subjects with the range of average scores. $* p<0.05$ and $* * p<0.0$, Wilcoxon signed-rank test.

Table I Dryness, scaling, erythema, and itchiness on the scalp of subjects with AD or SD/PC at weeks 0,2 , and 4

\begin{tabular}{|c|c|c|c|c|c|c|c|c|c|}
\hline \multirow{2}{*}{$\frac{\text { Score }}{\text { Dryness }}$} & \multicolumn{3}{|c|}{ Total } & \multicolumn{3}{|l|}{ AD } & \multicolumn{3}{|c|}{ SD/PC } \\
\hline & Wo & W2 & W4 & Wo & W2 & W4 & Wo & W2 & W4 \\
\hline I (none) & 3 & 4 & 5 & I & I & 2 & 2 & 3 & 3 \\
\hline 2 (slight) & 11 & 16 & 17 & 6 & 10 & II & 5 & 6 & 6 \\
\hline 3 (mild) & 12 & 6 & 7 & 8 & 3 & 2 & 4 & 3 & 5 \\
\hline 4 (moderate) & 5 & 7 & 5 & 2 & 4 & 4 & 3 & 3 & 1 \\
\hline 5 (severe) & 3 & I & 0 & 2 & 1 & 0 & $\mathrm{I}$ & 0 & 0 \\
\hline$p$-value & $*$ & $* *$ & - & ns & ns & - & ns & $*$ & \\
\hline \multicolumn{10}{|l|}{ Scaling } \\
\hline I (none) & 0 & 0 & 0 & 0 & 0 & 0 & 0 & 0 & 0 \\
\hline 2 (slight) & 4 & 15 & 15 & 3 & 10 & 9 & I & 5 & 6 \\
\hline 3 (mild) & 17 & 9 & 11 & 10 & 3 & 5 & 7 & 6 & 6 \\
\hline 4 (moderate) & 7 & 9 & 7 & 3 & 5 & 4 & 4 & 4 & 3 \\
\hline 5 (severe) & 6 & 1 & I & 3 & I & I & 3 & 0 & 0 \\
\hline$p$-value & - & $* *$ & $* *$ & - & $*$ & $*$ & - & $* *$ & $* *$ \\
\hline \multicolumn{10}{|l|}{ Erythema } \\
\hline I (none) & 6 & 6 & 12 & 2 & 2 & 6 & 4 & 4 & 6 \\
\hline 2 (slight) & 11 & 18 & 12 & 6 & 11 & 8 & 5 & 7 & 9 \\
\hline 3 (mild) & 8 & 3 & 8 & 6 & 2 & 3 & 2 & 1 & 0 \\
\hline 4 (moderate) & 7 & 7 & 2 & 4 & 4 & 2 & 3 & 3 & 0 \\
\hline 5 (severe) & 2 & 0 & 0 & 1 & 0 & 0 & I & 0 & 0 \\
\hline$p$-value & - & $* *$ & $* *$ & - & ns & $* *$ & - & ns & $* *$ \\
\hline \multicolumn{10}{|l|}{ Itchiness } \\
\hline I (none) & 2 & 6 & 9 & 2 & 5 & 6 & 0 & 1 & 3 \\
\hline 2 (slight) & 5 & 12 & 15 & 4 & 6 & 9 & 1 & 6 & 6 \\
\hline 3 (mild) & 12 & 11 & 5 & 6 & 5 & 2 & 6 & 6 & 3 \\
\hline 4 (moderate) & 15 & 4 & 4 & 7 & 2 & I & 8 & 2 & 3 \\
\hline 5 (severe) & 0 & I & I & 0 & I & 1 & 0 & 0 & 0 \\
\hline$p$-value & - & $* *$ & $* *$ & - & $*$ & $* *$ & - & $* *$ & $* *$ \\
\hline
\end{tabular}

Notes: ${ }^{*} p<0.05,{ }^{* *} p<0.01$, and "ns" indicates no significant difference from week 0 . Obtained using the Wilcoxon signed-rank test.

Abbreviations: $A D$, atopic dermatitis; SD, seborrheic dermatitis; PC, pityriasis capitis. 

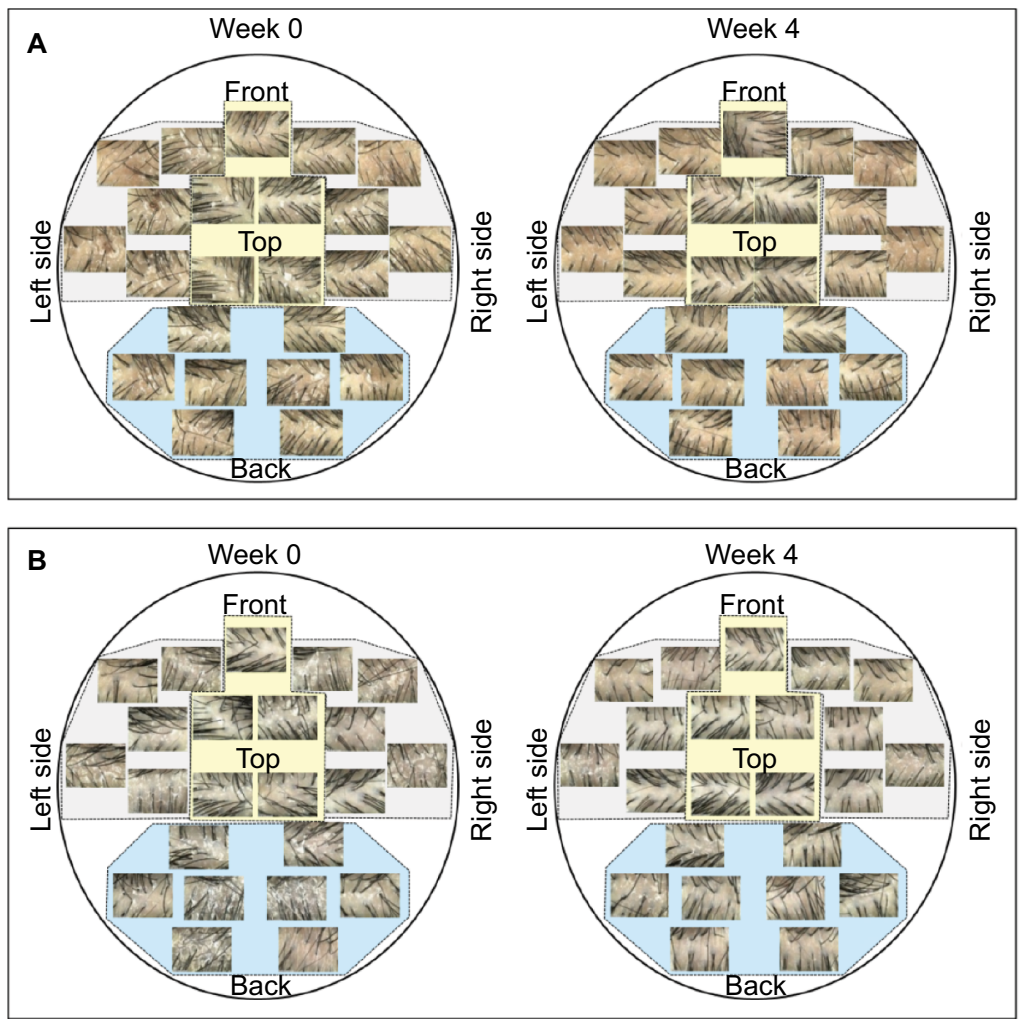

Figure 5 Typical clinical features at weeks 0 and 4 .

Notes: (A) A 23-year-old female subject with mild atopic dermatitis. (B) A 51 -year-old female subject with seborrheic dermatitis.

clinical improvement of the symptoms on the different areas of the head. In patients with atopic dermatitis (Figure 5A) and in those with seborrheic dermatitis (Figure 5B), scaling and erythema on all areas of the scalp were diminished at the end of the study.

Itchiness, measured using the VAS, improved significantly at weeks 2 and 4 (Figure 6), and the MRA gradually and significantly increased at weeks 2 and 4 (Figure 7A). The average TEWL value of all subjects at week 0 was consistent with the TEWL value of healthy scalp skin $(6.6 \pm 1.6 \mathrm{~g} /$ $\mathrm{m}^{2}$.hour $)^{21}$ and there were no significant changes during the test period (Figure 7B).

No adverse events due to treatment with the test material were recorded in the diary kept by each subject throughout this evaluation. From this result and the inquiry at each visual evaluation at weeks 2 and 4, this scalp lotion was judged as "safe" for all subjects.

Analysis by the Skindex-16 revealed significant improvements in symptoms, emotions, functioning, and globally at week 4 (Figure 8).

\section{Discussion}

The scalps of patients with seborrheic dermatitis or pityriasis capitis have lower ceramide levels in their stratum

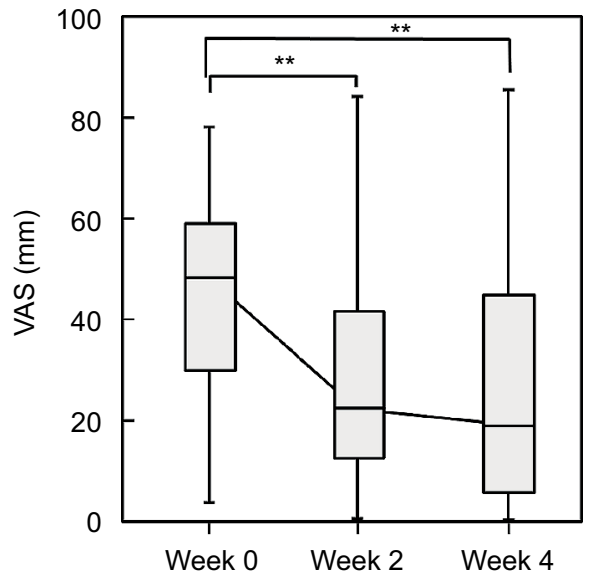

Figure 6 Itchiness evaluated by VAS at weeks 0,2 , and $4.0 \mathrm{~mm}$ indicates no itch and $100 \mathrm{~mm}$ represents a maximum intensity of itch.

Note: ${ }^{* *} p<0.01$, a significant difference from week 0 , obtained using a one-way repeated measures analysis of variance test.

Abbreviation: VAS, visual analog scale.

corneum. ${ }^{15,22}$ This decrease in ceramide induces a lower MRA and cutaneous barrier function, causing skin diseases such as atopic dermatitis. ${ }^{4,5}$ We have confirmed that the topical application of pseudo-ceramide (cetyl PG hydroxyethyl palmitamide) improves the decreased stratum corneum function of facial and body skin of patients with atopic dermatitis. ${ }^{10,12}$ Furthermore, we found that eucalyptus extract is effective in 
A

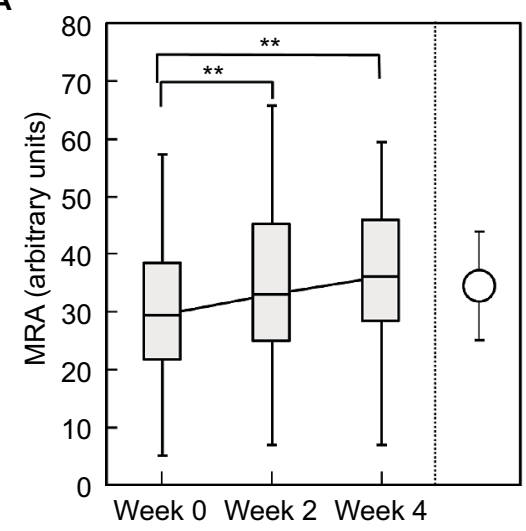

B

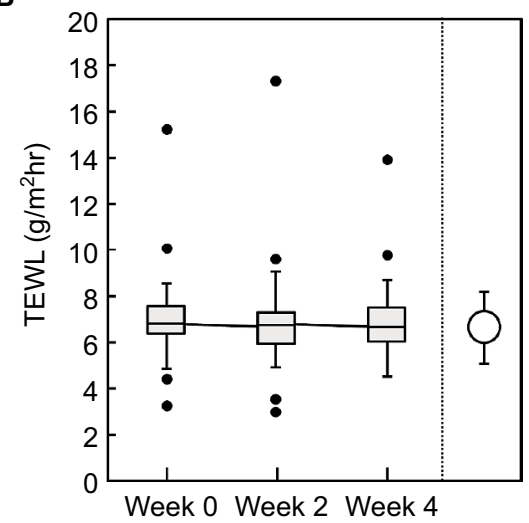

Figure 7 MRA (A) and TEWL (B) on the scalp at weeks 0, 2, and 4.

Notes: Open circles indicate the MRA and TEWL value of normal healthy scalp skin indicated in our previous report (average \pm SD). ${ }^{21} * * p<0.01$, a significant difference from week 0 , obtained using a one-way repeated measures analysis of variance test.

Abbreviations: MRA, moisture-retention ability; TEWL, transepidermal water loss.

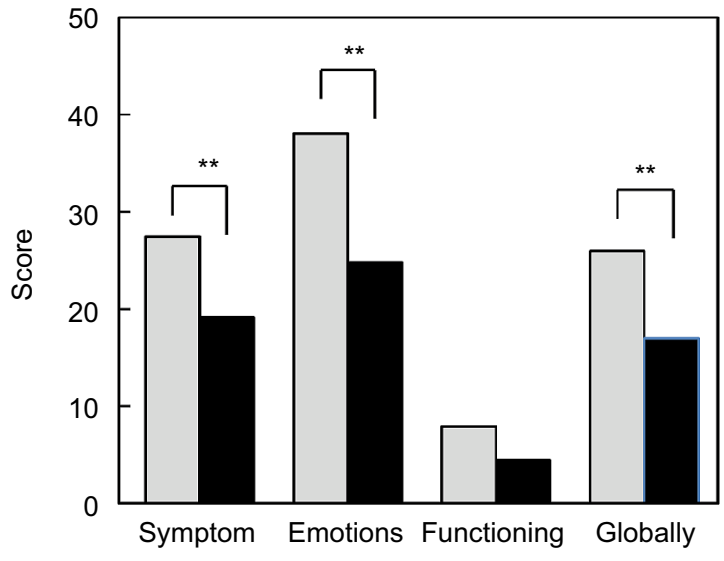

Week $0 \quad$ Week 4

Figure 8 QoL evaluated by the Skindex- $16^{\circledR}$ at weeks 0 and 4 .

Note: ${ }^{* *} p<0.01$, a significant difference from week 0 , obtained using a one-way repeated measures analysis of variance test.

Abbreviation: QoL, quality of life.

increasing ceramide levels in the epidermis. ${ }^{16}$ In this study, we clarified the efficacy of the topical application of a lotion containing pseudo-ceramide and eucalyptus extract on the dry and scaly scalps of patients with atopic dermatitis, seborrheic dermatitis, or pityriasis capitis, as shown by the decrease of scaliness, erythema, and itchiness.

In this evaluation, all subjects constantly had scalp symptoms prior to evaluation. Furthermore, there were only slight changes in the climate environment, such as the daily temperature and humidity, around weeks 0,2 , and 4 , even though the daily relative humidity did change. Additionally, changes of shampoo, conditioner, hair styling products and hair care products, and hair perms or coloration were prohibited during this study. Thus, we conclude that any changes in scalp

conditions are caused by usage of the scalp lotion. Because the subjects used various shampoos, conditioners, and hair styling products each day, the selection of a placebo scalp lotion was quite difficult. For these reasons, this evaluation was performed as a single dermatologist-controlled baseline comparison study.

Because of the presence of pseudo-ceramides in the lotion, the total ceramide level in the scalp could not be analyzed in this study. However, we have previously confirmed that a topically applied eucalyptus extract increases the ceramide level of the stratum corneum in the scalp. ${ }^{23}$ Furthermore, the pseudo-ceramide remained in the stratum corneum for 16 hours after topical application (data not shown). Since the efficacy of topically applied ceramides, pseudo-ceramides, or ceramide precursors on atopic dermatitis has been reported, ${ }^{8-13}$ it is surmised that both increased ceramide and applied pseudo-ceramides might improve the condition of the stratum corneum.

Cleansing with high-performance detergent is also a major factor that induces skin irritation by extracting natural moisturizing factors ${ }^{24}$ and intercellular lipids. ${ }^{25}$ However, in this study, the subjects did not change their shampoos, conditioners, or hair styling products. Thus, this study clarified the efficacy of the scalp lotion to increase ceramide levels to improve scalp conditions, as it does in other areas of the body for patients with atopic dermatitis. ${ }^{10,12}$

Two subjects with moderate atopic dermatitis had an oral medical treatment to take care of their body skin symptoms. Both of them ingested an antihistamine medicine and they had kept taking this medicine before the start of this evaluation. The dermatologist judged that this medication would have no effect on the stratum corneum condition and unless 
changing this treatment, this oral medical treatment may have little or no effect on result. Thus, they kept taking that same medication.

There were no statistically significant changes in TEWL during the 4-week test period. The subjects in the study had TEWL value similar to that of a healthy scalp $(6.6 \pm$ $1.6 \mathrm{~g} / \mathrm{m}^{2} \cdot$ hour $),{ }^{24}$ so changes of the TEWL value, if any, were too small to be detected.

There was no control group who did not use a scalp lotion but there were only small changes in temperature and relative humidity during this period (average temperature and relative humidity at the week 4 evaluation was almost same the week 0 evaluation). Thus, the environment might have less effect on the improvement of scalp conditions.

There are several studies of the placebo effects on itch. ${ }^{26}$ Because there were no placebo treatments, it is presumed that the decrease in itchiness might be caused by placebo effects, but the improvement of other skin symptoms, such as dryness, scaling, and erythema support the improvement of itchiness by this test scalp lotion.

Analysis by the Skindex-16 revealed significant improvements in symptoms, emotions, functioning, and globally at week 4. Functioning was also improved but the score at week 0 was low and thus the decrease was not significantly different. Similar to the improvements of itchiness, some proportion of the benefit may be due to a placebo effect, but improvements of dryness, scaling, and erythema, and also the increase in MRA support the improvements of QoL.

\section{Limitations}

There are some limitations to this study that need to be addressed in future studies. 1) The study assessed only females and whether similar effects occur on males with these skin diseases needs to be assessed. 2) The study did not include a control lotion without pseudoceramide nor eucalyptus extracts, so lotions with either of those actives or none should be performed to clarify which active(s) are effective. 3 ) The study covered only 4 weeks of evaluations, so whether a longer-term study would identify continued beneficial effects, or potentially adverse effects, should be elucidated.

\section{Conclusion}

From these data, the efficacy of the daily applications of a scalp lotion containing pseudo-ceramide and a eucalyptus extract to increase the MRA and improve the condition of the scalp was shown and the QoL of the patients was improved through the use of this lotion.

\section{Acknowledgments}

We thank Dr Hidetoshi Taima, Mr Shinzo Osumi, Mr Yosuke Inoue, and Ms Yuka Yasuda for their assistance in skin measurements and analysis of data, and we thank $\mathrm{Mr}$ Koichi Ishida for his critique of the findings of this study. This study was funded in full by Kao Corporation. Inforward Inc. received clinical trial implementation costs from Kao Corporation.

\section{Author contributions}

All authors contributed toward data analysis, drafting and revising the paper and agree to be accountable for all aspects of the work.

\section{Disclosure}

Akihiko Takahashi, Xuanhe Ning, Takahiro Nishizaka, Kazuhiro Kaizu, Masahiro Miyaki, Yutaka Takagi, and Hotaka Yamamuro are employees of the Kao Corporation. Chiaki Ishizaki is an employee of Inforward Inc. Makoto Kawashima received an honorarium from Kao Corporation for supervising this study. The authors report no other conflicts of interest in this work.

\section{References}

1. Lampe MA, Burlingame AL, Whitney J, et al. Human stratum corneum lipids: characterization and regional variations. J Lipid Res. 1983;24(2):120-130.

2. Elias PM, Brown BE. The mammalian cutaneous permeability barrier: defective barrier function is essential fatty acid deficiency correlates with abnormal intercellular lipid deposition. Lab Invest. 1978;39(6):574-583.

3. Imokawa G, Hattori M. A possible function of structural lipids in the water-holding properties of the stratum corneum. J Invest Dermatol. 1985;84(4):282-284.

4. Werner Y, Lindberg M, Forslind B. The water-binding capacity of stratum corneum in dry non-eczematous skin of atopic eczema. Acta Derm Venereol. 1982;62(4):334-337.

5. Taïeb A. Hypothesis: from epidermal barrier dysfunction to atopic disorders. Contact Dermatitis. 1999;41(4):177-180.

6. Melnik B, Hollmann J, Plewig G. Decreased stratum corneum ceramides in atopic individuals - a pathobiochemical factor in xerosis? Br J Dermatol. 1988;119(4):547-549.

7. Imokawa G, Abe A, Jin K, Higaki Y, Kawashima M, Hidano A. Decreased level of ceramides in stratum corneum of atopic dermatitis: an etiologic factor in atopic dry skin? J Invest Dermatol. 1991;96(4):523-526.

8. Imokawa G, Akasaki S, Kawamata A, Yano S, Takaishi N. Waterretaining function in the stratum corneum and its recovery properties by synthetic pseudoceramides. J Soc Cosmet Chem. 1989;40(5): 273-285.

9. Chamlin SL, Frieden IJ, Fowler A, et al. Ceramide-dominant, barrierrepair lipids improve childhood atopic dermatitis. Arch Dermatol. 2001;137(8):1110-1112.

10. Hata M, Tokura Y, Takigawa M, Tamura, Y, Imokawa G. Efficacy of using pseudoceramide-containing cream for the treatment of atopic dry skin in comparison with urea cream. Nishi Nihon Hifuka. 2002;64(5): 606-611. 
11. Simpson E, Böhling A, Bielfeldt S, Bosc C, Kerrouche N. Improvement of skin barrier function in atopic dermatitis patients with a new moisturizer containing a ceramide precursor. J Dermatolog Treat. 2013;24(2):122-125.

12. Imokawa $G$, Ishida $K$. Role of ceramide in the barrier function of the stratum corneum, implications for the pathogenesis of atopic dermatitis. J Clin Exp Dermatol Res. 2014;5:1-12.

13. Seghers AC, Cai SC, Ho MS, et al. Evaluation of a pseudoceramide moisturizer in patients with mild-to-moderate atopic dermatitis. Dermatol Ther (Heidelb). 2014;4(1):83-92.

14. Elewski BE. Clinical diagnosis of common scalp disorders. J Invest Dermatol Symp Proc. 2005;10(3):190-193.

15. Harding CR, Moore AE, Rogers JS, Meldrum H, Scott AE, McGlone FP. Dandruff: a condition characterized by decreased levels of intercellular lipids in scalp stratum corneum and impaired barrier function. Arch Dermatol Res. 2002;294(5):221-230.

16. Ishikawa J, Shimotoyodome Y, Chen S, et al. Eucalyptus increases ceramide levels in keratinocytes and improves stratum corneum function. Int J Cosmet Sci. 2012;34(1):17-22.

17. Tagami H, Kobayashi H, Zhen XS, Kikuchi K. Environmental effects on the functions of the stratum corneum. J Investig Dermatol Symp Proc. 2001;6(1):87-94.

18. Rajka G, Langeland T. Grading of the severity of atopic dermatitis. Acta Derm Venereol Suppl (Stockh). 1989;144:13-14.

19. Chen YC, Chiu WT, Wu MS. Therapeutic effect of topical gammalinolenic acid on refractory uremic pruritus. Am J Kidney Dis. 2006;48(1):69-76.
20. Higaki Y, Kawamoto K, Kamo T, Horikawa N, Kawashima M, Chren MM. The Japanese version of skindex-16: a brief quality-of-life measure for patients with skin diseases. J Dermatol. 2002;29(11):693-698.

21. Takagi Y, Takatoku H, Terazaki H, Nakamura T, Ishida K, Kitahara T. The scalp has a lower stratum corneum function with a lower sensory input than other areas of the skin evaluated by the electrical current perception threshold. Cosmetics. 2015;2(4):384-393.

22. Kerr K, Darcy T, Henry J, et al. Epidermal changes associated with symptomatic resolution of dandruff: biomarkers of scalp health. Int J Dermatol. 2011;50(1):102-113.

23. Takagi Y, Nojiri H, Taguchi H, Fukuda R, Mamada A. Barrier function of scalp, which has lower than that of others region, can be improved by increase in ceramide level by eucalyptus extract. Poster presented at: Annual Meeting of Chinese Journal of Dermatovenereology of Integrated Traditional and Western Medicine; September 2006; Shanghai.

24. Prottey C, Ferguson T. Factors which determine the skin irritation potential of soaps and detergents. J Soc Cosmet Chem. 1975;26(1): $29-46$.

25. Takagi Y, Nakagawa H, Higuchi K, Imokawa G. Characterization of surfactant-induced skin damage through barrier recovery induced by pseudoacylceramides. Dermatology. 2005;211(2):128-134.

26. van Laarhoven AIM, van der Sman-Mauriks IM, Donders ART, Pronk MC, van de Kerkhof PCM, Evers AWM. Placebo effects on itch: a metaanalysis of clinical trials of patients with dermatological conditions. J Invest Dermatol. 2015;135(5):1234-1243.
Clinical, Cosmetic and Investigational Dermatology

\section{Publish your work in this journal}

Clinical, Cosmetic and Investigational Dermatology is an international, peer-reviewed, open access, online journal that focuses on the latest clinical and experimental research in all aspects of skin disease and cosmetic interventions. This journal is included on PubMed. The manuscript management system is completely online

\section{Dovepress}

and includes a very quick and fair peer-review system, which is all easy to use. Visit http://www.dovepress.com/testimonials.php to read rea quotes from published authors 